\title{
Cognitive effects of a dietary supplement made from extract of Bacopa monnieri, astaxanthin, phosphatidylserine, and vitamin $E$ in subjects with mild cognitive impairment: a noncomparative, exploratory clinical study
}

This article was published in the following Dove Press journal:

Neuropsychiatric Disease and Treatment

3 February 2014

Number of times this article has been viewed

\section{Danilo Zanotta \\ Silvana Puricelli \\ Guido Bonoldi}

Unità Operativa di Medicina 2, Ospedale di Circolo di Busto

Arsizio, Varese, Italy
Correspondence: Danilo Zanotta Unità Operativa di Medicina 2, Ospedale di Circolo di Busto Arsizio, Piazzale G Solaro 3, Busto Arsizio 21052, Varese, Italy Tel +390331699269

Fax +390331699370

Email zanottadanilo@gmail.com

\begin{abstract}
A prospective cohort, noncomparative, multicenter trial was conducted to explore the potential of a phytotherapeutic compound, available as a dietary supplement and containing extracts of Bacopa monnieri and Haematococcus pluvialis (astaxanthin) plus phosphatidylserine and vitamin $\mathrm{E}$, in improving cognition in subjects diagnosed with mild cognitive impairment. Enrolled subjects $(n=104)$ were aged 71.2 \pm 9.9 years and had a mini-mental state examination score of 26.0 \pm 2.0 (mean \pm standard deviation). They underwent the Alzheimer's Disease Assessment Scale-cognitive subscale (ADAS-cog) test and the clock drawing test at baseline and upon completion of a 60-day period of dietary supplementation with one tablet daily of the tested compound. In 102 assessable subjects, total ADAS-cog scores improved from 13.7 \pm 5.8 at baseline to $9.7 \pm 4.9$ on day 60 , and the clock drawing test scores improved from $8.5 \pm 2.3$ to $9.1 \pm 1.9$. Both changes were statistically significant $(P<0.001)$. Memory tasks were the individual components of ADAS-cog showing the largest improvements. In a multivariate analysis, larger improvements in total ADAS-cog score were associated with less compromised baseline mini-mental state examination scores. Perceived efficacy was rated as excellent or good by $62 \%$ of study subjects. The tested compound was well tolerated; one nonserious adverse event was reported in the overall study population, and perceived tolerability was rated excellent or good by $99 \%$ of the subjects. In conclusion, dietary supplementation with the tested compound shows potential for counteracting cognitive impairment in subjects with mild cognitive impairment and warrants further investigation in adequately controlled, longer-term studies.
\end{abstract}

Keywords: mild cognitive impairment, Bacopa monnieri, astaxanthin, ADAS-cog test, clock drawing test, dietary supplement

\section{Introduction}

Most people experience gradual cognitive decline as they age. Some of them are suffering from what is commonly known as mild cognitive impairment (MCI), which is a more serious reduction in mental efficiency than the physiological agerelated decline but does not meet the criteria for a diagnosis of senile dementia or Alzheimer's disease. ${ }^{1-4}$

The estimated prevalence of MCI is between $10 \%-20 \%$ of people aged over $65,{ }^{5-10}$ and the causes of MCI are currently unknown. As with more severe forms of dementia, it is believed that MCI origin is complex, and that it involves factors that are toxic to nerve 
cells, such as $\beta$-amyloid protein, Tau protein and Lewy bodies (although these same pathological markers have also been found in elderly asymptomatic individuals), or alterations in cerebral circulation such as localized microstrokes. ${ }^{11}$

Several longitudinal studies have shown that the majority of people affected by MCI have a substantially increased risk of developing dementia. ${ }^{5-7,9}$ Whereas the incidence of dementia in the general population of the United States is $1 \%-2 \%$ per year, incidence in the MCI population reaches $5 \%-10 \%$ per year ${ }^{12}$ and $10 \%-15 \%$ in the subjects who are followed in specialist clinics. ${ }^{13}$

Therefore early recognition of MCI, leading to early intervention, might allow for preventing or delaying the onset of dementia and prolonging the active life of these subjects. However, despite some data suggesting that the rate of reversion of MCI patients to a normal cognitive level could be between $25 \%-30 \%$, prospective studies have shown lower rates. ${ }^{8}$

The main objective of the present study was to explore the potential of a phytotherapeutic compound, commercially available as dietary supplement and containing extracts of Bacopa monnieri and Haematococcus pluvialis (astaxanthin) plus phosphatidylserine and vitamin $\mathrm{E}$, in improving cognition in subjects diagnosed with MCI. A secondary objective was to assess the tolerability and safety of use of the compound.

Bacopa monnieri is a medicinal plant species traditionally used as a brain tonic. Studies conducted in animal models suggest that bacoside constituents of Bacopa monnieri have an antioxidant effect on the hippocampus, frontal cortex, and the striatum. ${ }^{14-17}$ A systematic review of several randomized, double-blind clinical studies conducted with Bacopa has demonstrated efficacy in improving memory and some cognitive functions. ${ }^{18}$

Astaxanthin is a carotenoid that is positioned within the cell membranes and the circulating lipoproteins and is not produced by human metabolism. It plays an antiinflammatory and antioxidant role ${ }^{19-21}$ and protects the plasma membrane and the double mitochondrial membrane. ${ }^{22}$ In a 12-week open study conducted in healthy subjects aged 50 to 69 years, oral administration of astaxanthin led to an improvement in some cognitive functions, such as reaction time, attention, and working memory. ${ }^{23}$

Phosphatidylserine is a phospholipid that becomes a key constituent of the cell membrane. ${ }^{24}$ It is found in high concentrations in the cerebral tissue, where it supports cellular functions such as maintenance of integrity of mitochondrial membranes for the production of energy, electrical depolarization of neuronal membranes, release of neurotransmitters in the synaptic cleft, postsynaptic receptor activity, and activation of protein kinase C. ${ }^{25-30}$
Vitamin E has antioxidant properties: it prevents the spread of oxidation of the polyunsaturated fatty acids by scavenging the lipid peroxyl radicals. The potential therapeutic or preventive role of vitamin $\mathrm{E}$ in brain aging and age-related cognitive disorders is still a subject of debate. ${ }^{31}$ While large-scale clinical trials have failed to demonstrate major cognitive benefits, vitamin E deficiency has been consistently found to be associated with Alzheimer's disease and MCI in recent human studies. ${ }^{31}$

\section{Materials and methods \\ Tested compound}

The tested compound is available as a dietary supplement in a tablet formulation (Illumina ${ }^{\circledR}$ ) and was supplied free of charge by Cristalfarma (Milan, Italy) for use in the study. Its composition is shown in Table 1.

\section{Subjects}

Subjects aged $\geq 50$ years referred to outpatient clinics of the participating centers due to forgetfulness, disorientation, difficulty in concentrating or other cognitive difficulties, and diagnosed with MCI were eligible for the study. MCI diagnosis was based on a mini-mental state examination ${ }^{32}$ (MMSE) score $\geq 22$ and $<28$ and on caregiver testimony on cognitive symptoms.

Subjects with known current psychiatric disorders or organic diseases that could interfere with the cognitive status were excluded, as were those undergoing treatment with any psychotropic drug.

All enrolled subjects provided written informed consent for participation in the study.

\section{Study design}

This was a prospective cohort, noncomparative, multicenter trial conducted at seven Italian outpatient clinics for agerelated cognitive disorders.

Baseline assessments included medical history, review of current therapies, physical examination, geriatric assessment, and MMSE, followed by the administration of the Alzheimer's

Table I Qualitative and quantitative composition of Illumina ${ }^{\circledR}$

\begin{tabular}{ll}
\hline Components & $\begin{array}{l}\text { Content } \\
\text { per tablet }\end{array}$ \\
\hline Microalgae (Haematococcus pluvialis) dry extract 3\% & $74 \mathrm{mg}$ \\
Astaxanthin & $2 \mathrm{mg}$ \\
Bacopa monnieri dry extract 20\% & $100 \mathrm{mg}$ \\
Bacosides & $20 \mathrm{mg}$ \\
Phosphatidylserine (extracted from soy) & $30 \mathrm{mg}$ \\
Vitamin E (vegetable origin) & $30 \mathrm{mg}$ \\
\hline
\end{tabular}

Note: Illumina ${ }^{\circledR}$ (Cristalfarma, Milan, Italy). 
Disease Assessment Scale-cognitive subscale (ADAS-cog) test $^{33}$ and the clock drawing test (CDT). ${ }^{34}$ Subjects were instructed in the presence of the respective caregivers to take one tablet of Illumina per day immediately before their main meal, for 60 days. Instructions and contact details were provided to subjects and caregivers should the need arise to report to investigators any adverse events occurring over the treatment period.

On day $60 \pm 3$, subjects were reassessed for intercurrent medical history, including adverse events and therapy changes. ADAS-cog and CDT were readministered by the same investigating physician. Subjects were asked to rate the perceived efficacy and tolerability of the treatment on 5-point scales. Each investigating physician could record free-text comments on individual treatment outcome.

\section{Neuropsychological tests}

The MMSE has a total score of 0-30 points. It was given to assess baseline cognitive status and to exclude the presence of any intellectual deficit. The lower limit for inclusion (22 points) was intended to exclude cognitive deterioration due to Alzheimer's disease or other forms of dementia.

ADAS-cog and CDT were given to assess cognitive skills. CDT examines the subject's planning ability and constructive skills, whereas ADAS-cog assesses specific characteristics of cognitive efficiency that are sensitive to deterioration due to primary degenerative dementia. ADAS-cog includes eleven tasks, of which nine are related to functional assessment and two are objective memory tests.

\section{Statistics}

Univariate analysis of day 60 versus baseline changes in ADAS-cog and CDT scores was performed using the Student's $t$-test for paired data. Multivariate analysis of variance (MANOVA) for paired data was used to explore relationships of ADAS-cog and CDT score changes to baseline variables such as sex, age, MMSE, family history of cognitive disorders, and concomitant diseases. Data analysis was performed using the Statistical Package for Social Sciences (SPSS) version 20.0 (IBM Corporation, Armonk, NY, USA). The significance threshold was set at $P<0.05$. Data are reported as means \pm standard deviation unless noted otherwise.

\section{Results}

A total of 104 subjects were enrolled, 48 men and 56 women with mean age of $71.2 \pm 9.9$ years. Baseline MMSE score was 26.0 \pm 2.0 . A family history of cognitive disorders was present in 14 subjects (13.5\%). Among concomitant diseases recorded at baseline, those with a prevalence $\geq 3$ subjects included hypertension $(n=29)$, bone and joint disorders $(n=9)$, allergy to drugs or foods or environmental agents $(n=8)$, respiratory disorders $(n=4)$, and diabetes mellitus $(n=3)$. Concomitant use of drugs possibly affecting cognitive status was not reported for any subject at either baseline or over the 60-day observation period.

All 104 subjects were assessed for safety. As two subjects were lost to observation (one of them following a nonserious adverse event, as detailed below), 102 were included in the univariate analysis of efficacy. Of those, 98 had complete information on baseline variables and were thus included in the multivariate analysis.

Changes in total ADAS-cog score and CDT are shown in Table 2. ADAS-cog went from $13.7 \pm 5.8$ at baseline to $9.7 \pm 4.9$ on day 60 , a statistically significant improvement according to univariate analysis $(P<0.001)$. A significant improvement was also found in the CDT score, from $8.5 \pm 2.3$ to $9.1 \pm 1.9(P<0.001)$.

Changes in individual components of ADAS-cog are shown in Figure 1. There was a statistically significant improvement in each of the eleven items $(P \leq 0.02)$. The largest improvements were observed in memory tasks ("word recall" and "word recognition").

Multivariate analysis of total ADAS-cog score showed a statistically significant interaction between treatment effect and baseline MMSE $(P=0.009)$, in the sense that larger ADAS-cog improvements were associated with less compromised MMSE scores. Otherwise, changes in ADAS-cog individual components and in the CDT score did not appear to be significantly influenced by any of the baseline variables included in the multivariate model.

Only one adverse event was recorded, consisting of gastric disturbances in a subject who was taking concomitant oral corticosteroids. This led to discontinuation of Illumina upon the subject's decision.

Assessments of the perceived efficacy and tolerability of treatment were obtained from 93 and 96 subjects, respectively. Efficacy was rated as excellent by $16 \%$ of subjects, good by

Table 2 ADAS-cog and clock drawing test scores before and after treatment with Illumina ${ }^{\circledR}$

\begin{tabular}{lllllll}
\hline $\begin{array}{l}\text { Test } \\
\text { administered }\end{array}$ & Time & $\mathbf{N}$ & Mean & $\begin{array}{l}\text { Standard } \\
\text { deviation }\end{array}$ & t-test & P-value \\
\hline ADAS-cog & D0 & 102 & 13.65 & 5.78 & II.I77 & $<0.00 \mathrm{I}$ \\
& D60 & 102 & 9.65 & 4.89 & & \\
Clock drawing & D0 & 102 & 8.46 & 2.29 & -4.521 & $<0.00 \mathrm{I}$ \\
test & D60 & 102 & 9.07 & 1.92 & & \\
\hline
\end{tabular}

Note: Illumina ${ }^{\circledast}$ (Cristalfarma, Milan, Italy).

Abbreviations: ADAS-cog, Alzheimer's Disease Assessment Scale-cognitive subscale; D0, day 0; D60, day 60. 


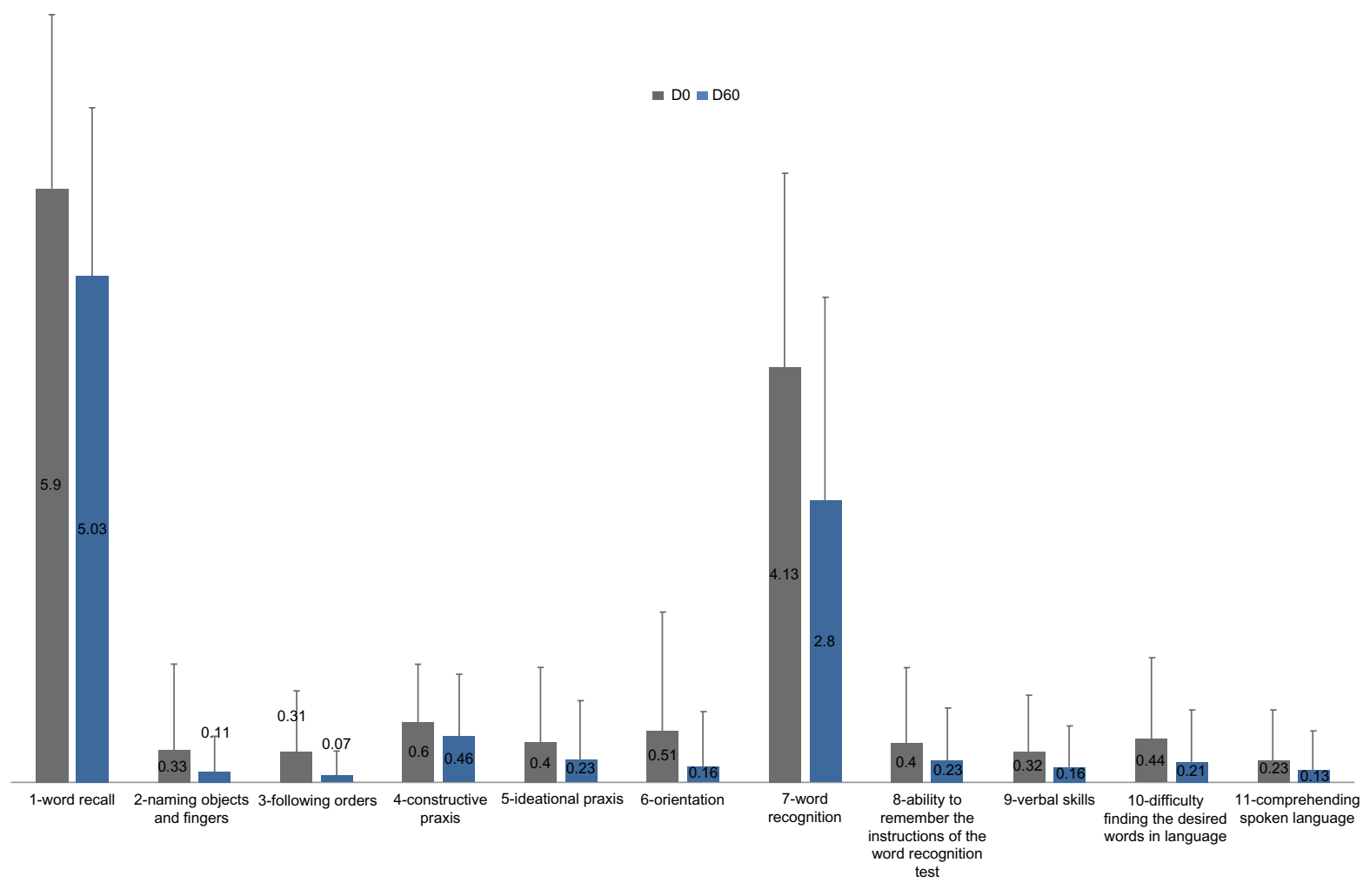

Figure I Mean \pm standard deviation scores of individual ADAS-cog components before and after treatment with Illumina ${ }^{\circledR}$.

Note: Illumina ${ }^{\circledR}$ (Cristalfarma, Milan, Italy).

Abbreviations: ADAS-cog, Alzheimer's Disease Assessment Scale-cognitive subscale; D0, day 0; D60, day 60.

$46 \%$, fair by $28 \%$, and poor or of no use by the remaining $10 \%$. Tolerability was rated as excellent by $67 \%$ of the subjects, good by $32 \%$, and poor by $1 \%$.

Specific comments on treatment outcome were recorded by the investigating physicians for 17 subjects. All of the comments highlighted improvements in cognitive performance and/or, interestingly, in the quality or duration of night-time sleep.

\section{Discussion}

In this prospective cohort, noncomparative multicenter trial, short-term (60-day) dietary supplementation with Illumina, a phytotherapeutic compound containing extracts of Bacopa monnieri and Haematococcus pluvialis (astaxanthin), soyextracted phosphatidylserine, and vitamin $\mathrm{E}$ of vegetable origin, was associated with an improvement in cognitive and mnemonic skills in subjects diagnosed with MCI. Cognitive and mnemonic performance was assessed with validated instruments (ADAS-cog and CDT) having predictive value for the risk of MCI progression to Alzheimer's disease. ${ }^{35}$ The observed 60-day improvements in ADAS-cog and CDT were statistically significant as compared with baseline values and were borne out by subject perception of treatment efficacy, which was rated as "excellent" or "good" in $62 \%$ of the cases.
The consumption of Illumina over 60 days was extremely well tolerated, as highlighted by rarity of the reported adverse events (one case out of 104 subjects) and by subject perception of compound tolerability ("excellent" or "good" in $99 \%$ of the cases).

These promising findings are of particular interest and relevance when considered in the context of MCI, a condition still posing a largely unmet medical need due to its prevalence in the elderly population, high associated risk for progression to Alzheimer's disease, and current lack of effective therapeutic or preventive measures. ${ }^{36}$

A basic limitation of the present study was the lack of a control treatment arm with consequent openness to selection bias and placebo effect. Thus the cognitive benefits observed with Illumina, while looking consistent with earlier observations made with other Bacopa monnieri or astaxanthin compounds, ${ }^{14-23}$ should be regarded as exploratory (hypothesis-raising). On the other hand, efficacy data were likely exempt from attrition bias, as the main analyses of ADAS-cog and CDT accounted for $98 \%$ of the enrolled subjects (102 out of 104). Other study limitations include a period of observation which may have been too short to adequately reflect the natural course of MCI and the lack of assessment of compliance to the tested dietary supplement. 


\section{Conclusion}

The results of this study show that dietary supplementation with Illumina has potential for counteracting cognitive impairment in subjects with MCI. Further investigation of this compound in adequately controlled, longer-term studies is warranted to formally assess its cognitive effects in mild or moderate mnemonic-cognitive disorders.

\section{Acknowledgments}

In addition to the authors, the following clinical investigators, all in Italy, collected data for this study: Orazio D'Alessio, consulting geriatrician, Hospital in Vasto; M Letizia Del Re, Psychogeriatrics Clinic and Alzheimer's Centre, Hospital in Pescara; Alberto Edalli, Raimondi Foundation, Gorla Minore; Paolo Genoni, "Scuola di Medicina Carnaghi e Brusatori" Foundation, Busto Arsizio; Walter Polinelli, DEWA Srl Milan; Fabio Matascioli, psychologist and psychotherapist, San Giorgio a Cremano. Statistical analysis was performed by Stella Forti, freelance consultant in medical statistics, Milan, Italy. The study was supported in part by an unrestricted grant from Cristalfarma, Milan, Italy.

\section{Disclosure}

The authors report no conflicts of interest in this study.

\section{References}

1. Petersen RC, Smith GE, Waring SC, Ivnik RJ, Tangalos EG, Kokmen E. Mild cognitive impairment: clinical characterization and outcome. Arch Neurol. 1999;56(3):303-308.

2. Petersen RC. Mild cognitive impairment as a diagnostic entity. J Intern Med. 2004;256(3):183-194.

3. Molano J, Boeve B, Ferman T, et al. Mild cognitive impairment associated with limbic and neocortical Lewy body disease: a clinicopathological study. Brain. 2010;133(Pt 2):540-556.

4. Petersen RC, Thomas RG, Grundman M, et al; Alzheimer's Disease Cooperative Study Group. Vitamin E and donepezil for the treatment of mild cognitive impairment. $N$ Engl J Med. 2005;352(23): 2379-2388.

5. Busse A, Hensel A, Gühne U, Angermeyer MC, Riedel-Heller SG. Mild cognitive impairment: long-term course of four clinical subtypes. Neurology. 2006;67(12):2176-2185.

6. Di Carlo A, Lamassa M, Baldereschi M, et al. CIND and MCI in the Italian elderly: frequency, vascular risk factors, progression to dementia. Neurology. 2007;68(22):1909-1916.

7. Plassman BL, Langa KM, Fisher GG, et al. Prevalence of cognitive impairment without dementia in the United States. Ann Intern Med. 2008;148(6):427-434.

8. Manly JJ, Tang MX, Schupf N, Stern Y, Vonsattel JP, Mayeux R. Frequency and course of mild cognitive impairment in a multiethnic community. Ann Neurol. 2008;63(4):494-506.

9. Lopez OL, Jagust WJ, DeKosky ST, et al. Prevalence and classification of mild cognitive impairment in the Cardiovascular Health Study Cognition Study: part 1. Arch Neurol. 2003;60(10):1385-1389.

10. Petersen RC, Roberts RO, Knopman DS, et al. Prevalence of mild cognitive impairment is higher in men. The Mayo Clinic Study of Aging. Neurology. 2010;75(10):889-897.
11. Anderton BH. Aging of the brain. Mech Aging Dev. 2002;123(7): 811-817.

12. Farias ST, Mungas D, Reed BR, Harvey D, DeCarli C. Progression of mild cognitive impairment to dementia in clinic- vs community-based cohorts. Arch Neurol. 2009;66(9):1151-1157.

13. Ganguli M, Chang CC, Snitz BE, Saxton JA, Vanderbilt J, Lee CW. Prevalence of mild cognitive impairment by multiple classifications: The Monongahela-Youghiogheny Healthy Aging Team (MYHAT) project. Am J Geriatr Psychiatry. 2010;18(8):674-683.

14. Bhattacharya SK, Bhattacharya A, Kumar A, Ghosal S. Antioxidant activity of Bacopa monniera in rat frontal cortex, striatum and hippocampus. Phytother Res. 2000;14(3):174-179.

15. Chowdhuri DK, Parmar D, Kakkar P, Shukla R, Seth PK, Srimal RC. Antistress effects of bacosides of Bacopa monnieri: modulation of Hsp70 expression, superoxide dismutase and cytochrome P450 activity in rat brain. Phytother Res. 2002;16(7):639-645.

16. Russo A, Borrelli F, Campisi A, Acquaviva R, Raciti G, Vanella A. Nitric oxide-related toxicity in cultured astrocytes: effect of Bacopa monniera. Life Sci. 2003;73(12):1517-1526.

17. Russo A, Izzo AA, Borrelli F, Renis M, Vanella A. Free radical scavenging capacity and protective effect of Bacopa monniera L. on DNA damage. Phytother Res. 2003;17(8):870-875.

18. Pase MP, Kean J, Sarris J, Neale C, Scholey AB, Stough C. The cognitive-enhancing effects of Bacopa monnieri: a systematic review of randomized, controlled human clinical trials. J Altern Complement Med. 2012;18(7):647-652.

19. McNulty HP, Byun J, Lockwood SF, Jacob RF, Mason RP. Differential effects of carotenoids on lipid peroxidation due to membrane interactions: X-ray diffraction analysis. Biochim Biophys Acta. 2007;1768(1):167-174.

20. Iwamoto T, Hosoda K, Hirano R, et al. Inhibition of low-density lipoprotein oxidation by astaxanthin. J Atheroscler Thromb. 2000;7(4): 216-222.

21. Park JS, Chyun JH, Kim YK, Line LL, Chew BP. Astaxanthin decreased oxidative stress and inflammation and enhanced immune response in humans. Nutr Metab (Lond). 2010;7:18.

22. Wolf AM, Asoh S, Hiranuma H, et al. Astaxanthin protects mitochondrial redox state and functional integrity against oxidative stress. J Nutr Biochem. 2010;21(5):381-389.

23. Satoh A, Tsuji S, Okada Y, et al. Preliminary clinical evaluation of toxicity and efficacy of a new astaxanthin-rich Haematococcus pluvialis extract. J Clin Biochem Nutr. 2009;44(3):280-284.

24. Alberts B, Johnson A, Lewis J, Raff M, Roberts K, Walter P. Molecular Biology of the Cell. 4th ed. New York, NY: Garland Science; 2002.

25. Kidd PM. PS (Phosphatidyl Serine), Nature's Brain Booster. 2nd ed. St George, UT: Total Health Communications; 2007.

26. Toffano G. The therapeutic value of phosphatidylserine effect in the aging brain. In: Hanin L, Ansell GB, editors. Lecithin: Technological, Biological and Therapeutic Aspects. New York: Plenum Press; 1987: 137-146.

27. Nunzi MG, Milan F, Guidolin E, Zanotti A, Toffano, G. Therapeutic properties of phosphatidylserine in the aging brain. In: Hanin I, Pepeu G, editors. Phospholipids: Biochemical, Pharmaceutical and Analytical Considerations. New York: Plenum Press; 1990:213-218.

28. Samson JC. The biological basis of phosphatidylserine pharmacology. Clin. Trials J. 1987;24(1):1-8

29. Borghese CM, Gómez RA, Ramírez OA. Phosphatidylserine increases hippocampal synaptic efficacy. Brain Res Bull. 1993;31(6) $697-700$.

30. Toffano G, Bruni A. Pharmacological properties of phospholipid liposomes. Pharmacol Res Commun. 1980;12(9):829-845.

31. Joshi YB, Praticò D. Vitamin E in aging, dementia, and Alzheimer's disease. Biofactors. 2012;38(2):90-97.

32. Folstein MF, Folstein SE, McHugh PR. "Mini-mental state". A practical method for grading the cognitive state of patients for the clinician. J Psychiatr Res. 1975;12(3):189-198. 
33. Rosen WG, Mohs RC, Davis KL. A new rating scale for Alzheimer's disease. Am J Psychiatry. 1984;141(11):1356-1364.

34. Libon DJ, Swenson R, Baronski EJ, Sands LP. Clock drawing as an assessment tool for dementia. Arch Clin Neuropsychol. 1993;8(5):405-415.

35. Rozzini L, Vicini Chilovi B, Bertoletti E, et al. The importance of Alzheimer disease assessment scale-cognitive part in predicting progress for amnestic mild cognitive impairment to Alzheimer disease. J Geriatr Psychiatry Neurol. 2008;21(4):261-267.
36. Cooper C, Li R, Lyketsos C, Livingston G. Treatment for mild cognitive impairment: systematic review. Br J Psychiatry. 2013;203: 255-264.

Neuropsychiatric Disease and Treatment

Dovepress

\section{Publish your work in this journal}

Neuropsychiatric Disease and Treatment is an international, peerreviewed journal of clinical therapeutics and pharmacology focusing on concise rapid reporting of clinical or pre-clinical studies on a range of neuropsychiatric and neurological disorders. This journal is indexed on PubMed Central, the 'PsycINFO' database and CAS.

The manuscript management system is completely online and includes a very quick and fair peer-review system, which is all easy to use. Visit http://www.dovepress.com/testimonials.php to read real quotes from published authors.

\footnotetext{
Submit your manuscript here: http://www.dovepress.com/neuropsychiatric-disease-and-treatment-journal
} 